\title{
Evaluation of adjacent tooth displacement in the posterior implant restoration with proximal contact loss by superimposition of digital models
}

\author{
Deuk-Won Jo , Min-Jung Kwon', Jong-Hee Kim¹, Young-Kyun Kim², Yang-Jin Yi³ ${ }^{3 *}$ \\ 'Department of Prosthodontics, Seoul National University Bundang Hospital, Seongnam, Republic of Korea, \\ ${ }^{2}$ Department of Oral \& Maxillofacial Surgery, Seoul National University Bundang Hospital, Seongnam, Dental Research Institute, \\ School of Dentistry, Seoul National University, Seoul, Republic of Korea \\ ${ }^{3}$ Department of Prosthodontics, Seoul National University Bundang Hospital, Seongnam, Dental Research Institute, School of \\ Dentistry, Seoul National University, Seoul, Republic of Korea
}

\begin{abstract}
PURPOSE. This study was conducted to investigate patterns of adjacent tooth displacement in the posterior implant with interproximal contact loss (ICL) by 3-D digital superimposition method. MATERIALS AND

METHODS. Posterior partially edentulous patients, restored with implant fixed partial prostheses before 2011 and suffered from food impaction of ICL between 2009 and 2011, were included. Two dental casts, at the time of delivery and at the time of food impaction in a same patient, was converted into 3-D digital models through scanning and superimposition was performed to assess chronologic changes of the dentition. Directions of tooth displacement were evaluated and the amount of ICL was calculated. Correlations between the amount of ICL and elapsed time, or between the amount of $\mathrm{ICL}$ and age after function, were assessed at a significance level of $P<.05$. RESULTS. A total number of 13 patients (8 males, 5 females) with a mean age of $65.76 \pm 9.94$ years and 17 areas (4 maxillae, 13 mandibles) were included in this retrospective study. Teeth adjacent to the implant restoration showed complex displacements but characteristic tendency according to the location of the arch. The mean amount of ICL was $0.33 \pm 0.14 \mathrm{~mm}$. Elapsed time from function to ICL was $61.47 \pm 31.27$ months. There were no significant differences between the amount of ICL and elapsed time, or age $(P>.05)$. CONCLUSION. Natural teeth showed various directional movements to result in occlusal change in the arch. The 3-D superimposition of chronologic digital models was a helpful method to analyze the changes of dentition and individual tooth displacement adjacent to implant restoration. [J Adv Prosthodont 2019;11:88-94]
\end{abstract}

KEYWORDS: Adjacent teeth; Dental implants; Digital; Proximal contact loss; Superimposition; Tooth displacement

\section{INTRODUCTION}

Nowadays, it is generally considered that implant treatments on partially edentulous patients are predictable restorative therapy. ${ }^{1-3}$ After implant restoration, however, a great num-

\footnotetext{
Corresponding author:

Yang-Jin Yi

Department of Prosthodontics, Seoul National University Bundang Hospital 82 Gumi-ro 173-gil, Bundang-gu, Seongnam 13620, Republic of Korea Tel. +82317877546: e-mail, navydent@snubh.org

Received September 12, 2018 / Last Revision February 11, 2019 /

Accepted April 17, 2019

(C) 2019 The Korean Academy of Prosthodontics

This is an Open Access article distributed under the terms of the Creative Commons Attribution Non-Commercial License (http://creativecommons. org/licenses/by-nc/4.0) which permits unrestricted non-commercial use, distribution, and reproduction in any medium, provided the original work is properly cited.
}

ber of complications associated implant prostheses have been reported. Biologic complications such as peri-implantitis and mucositis, or technical complications such as fracture of the veneer material, screw loosening, and loss of retention, were the most frequently encountered..$^{4-7}$

Food impaction from interproximal contact loss (ICL) between implant prostheses and adjacent natural teeth was a recently reported complication in the partially edentulous patient. ${ }^{8-11}$ Although this is a multifactorial complication from tooth migration, crown-related cause and bone formation/growth-related cause, ${ }^{12}$ interproximal contact loss phenomenon was related mainly with the tendency of mesial drift of natural tooth ${ }^{13,14}$ in the posterior region. Mesial tilting of tooth and anterior component of occlusal force were supposed as primary causes of inherent mesial drift of tooth in human being. ${ }^{15-17}$ The periodontal ligament 
between tooth and alveolar bone enables tooth to move, and alterations in natural tooth position persist throughout the whole life of human being. ${ }^{18,19}$ As shown in some case reports earlier, on the contrary, it could be said that the osseointegrated implant does not follow the skeletal growth and dentoalveolar complex change $e^{20,21}$ because of the direct contact forming between the implant and the alveolar bone similar to "ankylosis". $20,22,23$

Many studies have reported the three dimensional (3D) superimposition was an effective clinical technique to evaluate tooth movements. ${ }^{24-26}$ However, pattern of mesial migration of natural tooth adjacent to implant restoration was not fully known yet. The present study was based on the considerations that adjacent natural tooth displacement could be analyzed from the superimposition of digital models scanned with unchanged implant location as references.

The purpose of this study was to investigate patterns of natural tooth displacement adjacent to posterior implant restorations with interproximal contact loss. Moreover, we evaluated whether 3D scanning was effective modality to analyze displacement of adjacent teeth in the implant restorations.

\section{MATERIALS AND METHODS}

In this retrospective study, the subjects were patients who were restored with implants in the posterior region at Seoul National University Bundang Hospital, Department of Dentistry by two prosthodontists (HJW and YYJ) before 2011, and were suffering from food impaction with ICL between 2009 and 2011. All restoration procedures had been performed based on the fixture level impression system of internal connection implant. All proximal contact and occlusion was checked at the time of delivery of implant restoration. Patients signed informed consent of complication after restoration and recalled every 6 months. In every follow up, one prosthodontist (YYJ) examined periapical view, occlusion, and proximal contact with floss silk, and asked any discomfort to all patients. When food impaction occurred, interproximal gap was confirmed by dental floss resistance test and visual inspection. The first recognized time of food impaction after implant restoration was asked and set as the elapsed time.

Among the patients with food impaction due to ICL, inclusion criteria were: 1) who had an initial dental cast at the time of implant fixed prostheses delivery, to compare change of arch and individual tooth displacement, 2) who had a periodic follow up record, and 3) who had opposite dentition of natural teeth or fixed implant restoration. However, patients 1) with orthodontic treatment before implant, 2) with adjacent tooth restoration during follow up, 3) with parafunctional habit, 4) with moderate to severe periodontitis were excluded from the study.

This study was performed under the approval of Seoul National University Bundang Hospital's Institutional Review Board (IRB No. B-1212-182-110).

To analyze adjacent tooth displacements of selected patients, 3D scanning and 3D superimposition method were used. A new dental cast with ICL was compared and measured with an initial cast made when the implant fixed prosthesis was fabricated. Silicone impression was made for new dental cast of arch with ICL. After impression taking, implant superstructure (crown and abutment) was disconnected from the oral cavity and moved to initial cast for reconnection to original position. Both initial cast with superstructure reconnected and new cast with ICL were scanned using Rexcan DS2 3D model scanner (Solutionix, Seoul, Korea, resolution 1.3 mega pixel, point spacing $0.05 \mathrm{~mm}$ ). These scans were converted into 3D digital models, and these digital models were superimposed on each other. Axial wall of implant restoration, which is unchangeable, was used as a matching reference. Surrounding soft tissues were also considered as auxiliary references. Surface-to-surface superimposition process was automatically executed by the computer. For superimposition procedure, EZ scan (Solutionix, Seoul, Korea) CAD software was used.

Movements of the adjacent tooth and other dentition of the same arch to the reference of implant restoration were assessed by using transverse, sagittal, and coronal slice-cut image of superimposed digital models (Fig. 1). Same position of slice-cut images of two chronologic casts were compared and displacement patterns such as drift, tilting, rotation, and extrusion were recorded (Fig. 2). Whether adjacent teeth were splinted was also evaluated.

Widths of interproximal gap on ICLs were calculated. First, the magnification image of the interproximal gap was obtained by capturing the enlarged images of digitized ICL models. The gap width was measured using Image J program (National Institutes of Health, Bethesda, ME, USA). For actual interproximal gap width conversion, dental cast was gauged with a digital caliper with $0.01 \mathrm{~mm}$ accuracy (Mitutoyo Co., Kanagawa, Japan), and enlargement ratio was calculated. In order to verify the calculated width of interproximal gap, confirmation was reassured by placing the interproximal contact gauge (Swiss Dental Care, Zurich, Swiss) between the implant restoration and adjacent tooth on the dental cast with ICL. Widths of contact gauges used were $0.1,0.2,0.3,0.4$, and $0.5 \mathrm{~mm}$.

A statistical analysis was performed using SPSS 18.0. The Kendall's tau-b and Spearman's rho analysis at $P<.05$ level of significance were performed on the correlation between interproximal gap width and the elapsed time of ICL, or between interproximal gap width and age.

\section{RESULTS}

Thirteen patients ( 8 males and 5 females) and 13 dental arches (4 maxillae and 9 mandibles) were selected for this analysis. The mean age of patients was $65.76 \pm 9.94$ years. Of 13 patients, 4 patients have two restorations in both arches or two bilateral restorations in an arch. Therefore, 17 areas of ICL were included in the 4 maxillae and 13 mandibles. Twelve of 17 areas were free-end cases. All ICLs were found at the mesial aspect of implant restoration. A number 

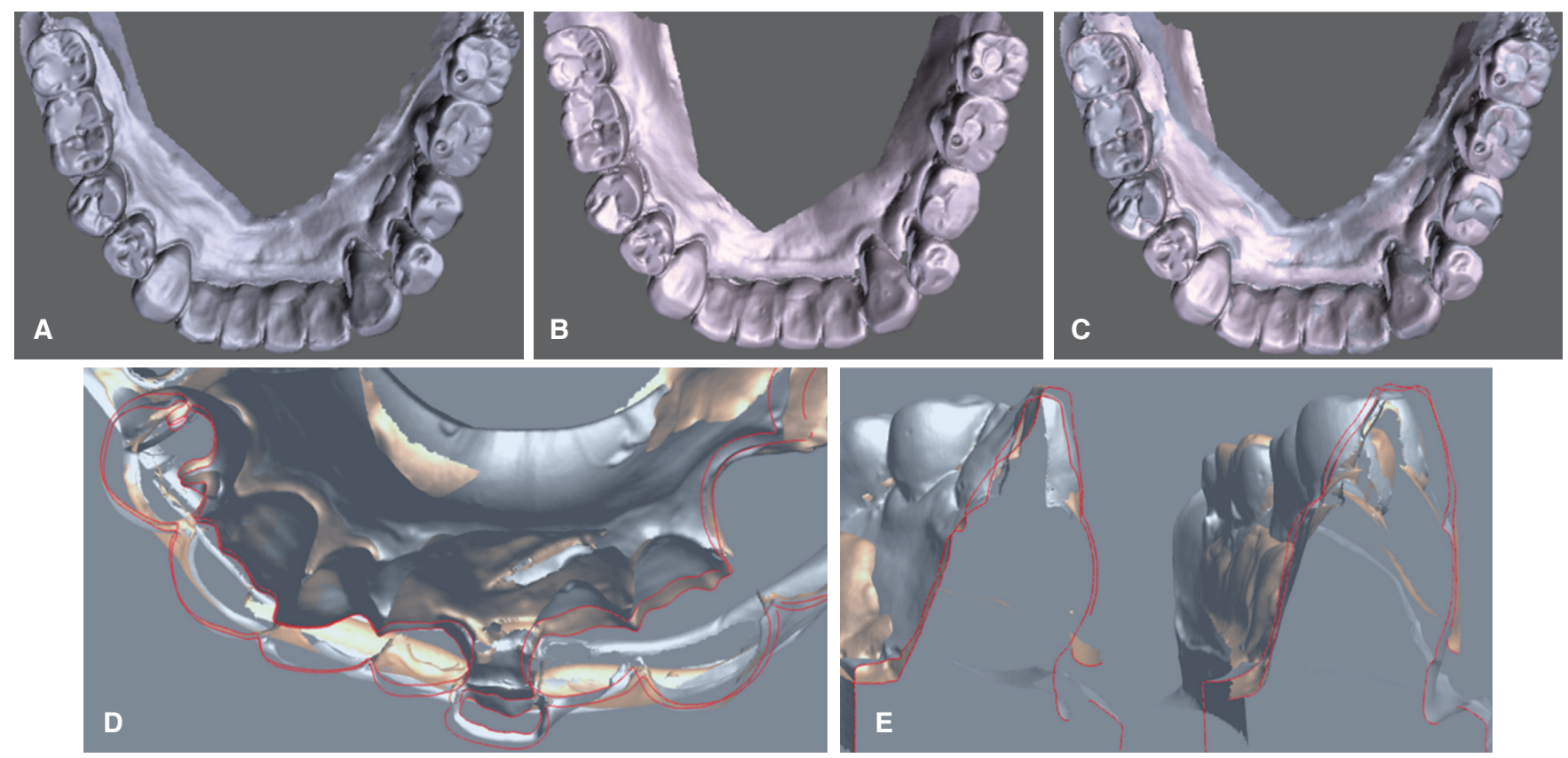

Fig. 1. 3-D digitally scanned images of dental casts. (A) initial model, (B) interproximal contact loss (ICL) model, (C) superimposition of two chronologic models, (D) occlusal view of superimposed incisors, (E) slice cut of superimposed images.

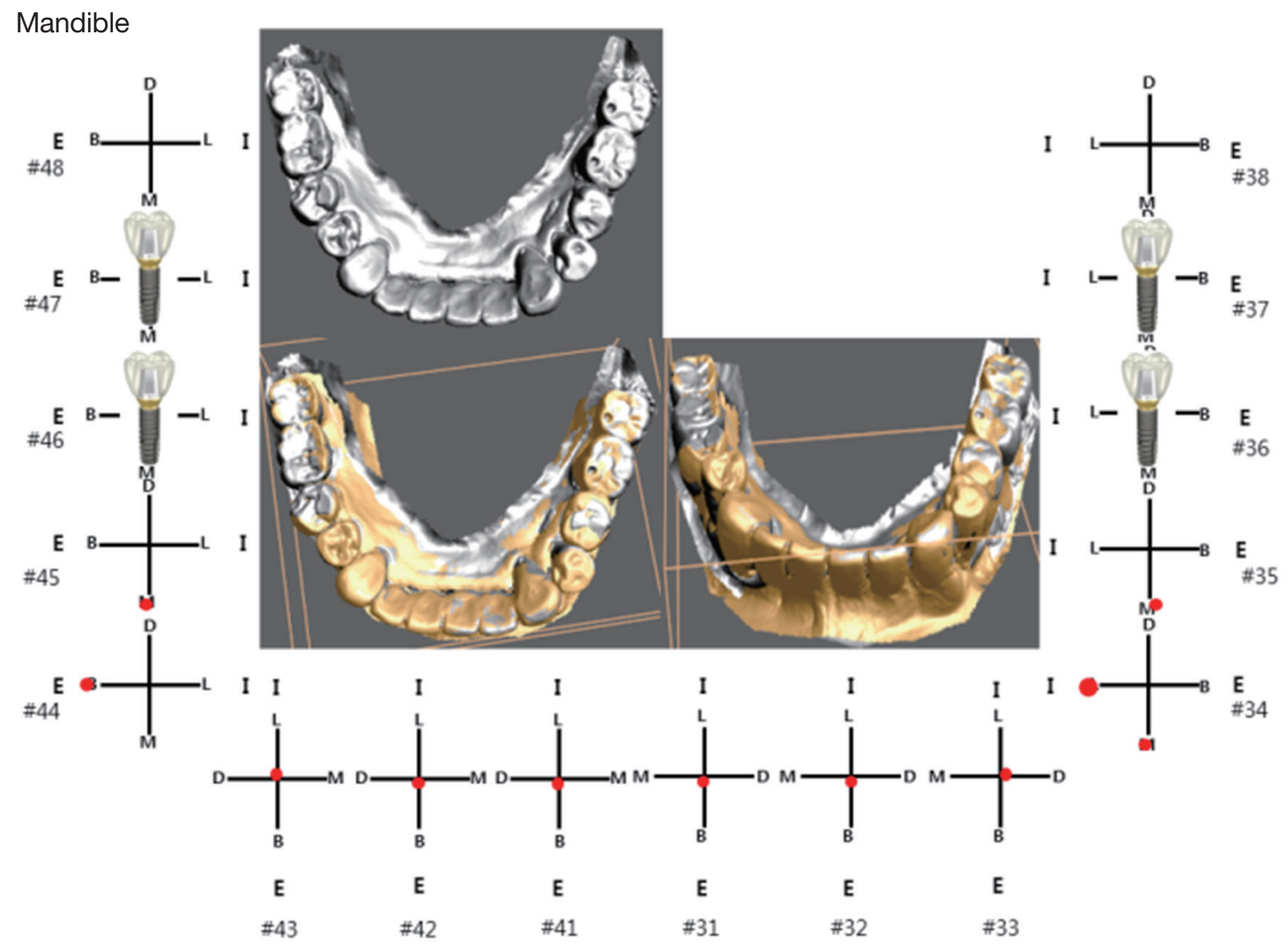

Fig. 2. Analysis diagram of regional displacement directions of natural teeth. 
of regions of ICL were 3 between maxilla premolar and molar, 1 between maxilla canine and premolar, 2 between mandible molars, 10 between mandible premolar and molar, and 1 between mandible premolars. 7 restorations were single implant restorations and 10 were splinted implant restorations. Meanwhile, among the 17 adjacent teeth of ICL areas, 6 were splinted. For opposite arches of the ICL, 5 were for implant restorations, 6 for natural teeth, and 6 for fixed prostheses of natural teeth (Table 1).
In classifying the prominent displacements of adjacent tooth to the implant restoration, 11 areas for mesial migrations, 4 for extrusions, 1 for lingual movement, and 1 for rotation were observed. Overall tooth movement was not unidirectional or not a single pattern of displacement, but showed three dimensional complex patterns (Fig. 3). In the arches with ICL, the movement patterns of adjacent teeth depend on the arch and location. Maxillary and mandibular molars/premolars primarily showed mesially drifted move-

Table 1. Distribution of ICL area, gap, and adjacent tooth displacement

\begin{tabular}{|c|c|c|c|c|c|c|c|c|}
\hline Patient & Sex & Age & $\begin{array}{c}\text { Area } \\
\text { (tooth-implant) }\end{array}$ & $\begin{array}{l}\text { Function until } \\
\text { measuring } \\
\text { (months) }\end{array}$ & $\begin{array}{l}\text { Interproximal } \\
\text { gap (mm) }\end{array}$ & $\begin{array}{l}\text { Prominent direction } \\
\quad \text { of adjacent } \\
\text { tooth displacement }\end{array}$ & $\begin{array}{l}\text { Adjacent } \\
\text { teeth } \\
\text { splinting }\end{array}$ & $\begin{array}{c}\text { Opposite } \\
\text { arch }^{c}\end{array}$ \\
\hline 1 & $F$ & 68 & $45-46|47|^{\star}$ & 91 & 0.2 & $\# 45 \mathrm{M}$ & S & I \\
\hline 2 & & & 34-35|36|37| & 91 & 0.27 & \#34M & S & $\mathrm{N}$ \\
\hline 3 & $\mathrm{~F}$ & 72 & $46-47 \mid$ & 13 & 0.26 & \#46E & NS & $\mathrm{N}$ \\
\hline 4 & M & 69 & $25-26 \mid$ & 8 & 0.52 & \#25M & NS & $\mathrm{N}$ \\
\hline 5 & $M$ & 62 & $46-47 \mid$ & 72 & 0.28 & \#46E & NS & F \\
\hline 6 & M & 78 & $15-16|17|$ & 74 & 0.24 & $\# 15 \mathrm{M}$ & S & I \\
\hline 7 & & & $35-36|37|$ & 57 & 0.28 & \#35E & NS & I \\
\hline 8 & $M$ & 69 & $35-36|37|$ & 96 & 0.49 & $\# 35 \mathrm{M}$ & NS & I \\
\hline 9 & & & $45-46|47|$ & 96 & 0.61 & $\# 45 \mathrm{M}$ & NS & F \\
\hline 10 & M & 72 & $45-46 \mid$ & 52 & 0.44 & $\# 45 \mathrm{M}$ & NS & F \\
\hline 11 & $\mathrm{~F}$ & 47 & $35-36|37|$ & 29 & 0.34 & \#35E & NS & $\mathrm{N}$ \\
\hline 12 & $\mathrm{~F}$ & 47 & $15-16 \mid$ & 91 & 0.33 & $\# 15 \mathrm{M}$ & NS & $\mathrm{N}$ \\
\hline 13 & M & 66 & $35-36|37|$ & 84 & 0.28 & \#35L & S & $\mathrm{N}$ \\
\hline 14 & & & $45-46|47|$ & 84 & 0.21 & $\# 45 \mathrm{M}$ & $S$ & $\mathrm{~N}$ \\
\hline 15 & $M$ & 59 & $35-361$ & 10 & 0.12 & \#35R & NS & $\mathrm{N}$ \\
\hline 16 & $\mathrm{~F}$ & 78 & $23-24 \mid=26 I 27 i$ & 50 & 0.53 & \#23M & S & $\mathrm{N}$ \\
\hline 17 & M & 50 & $45-461$ & 47 & 0.27 & $\# 45 \mathrm{M}$ & NS & I \\
\hline
\end{tabular}

*I: Implant

a: migration of adjacent natural tooth (M: mesial side, E: extrusion, L: lingual side, R: rotation)

b: Splinted status (S: splinted, NS: not splinted)

c: Implant (I), Natural tooth (N), and Fixed prostheses supported by natural tooth ( $\mathrm{F}$ )

\# 1 \& 2, 6 \& 7, 8 \& 9, 13 \& 14 were same patient.

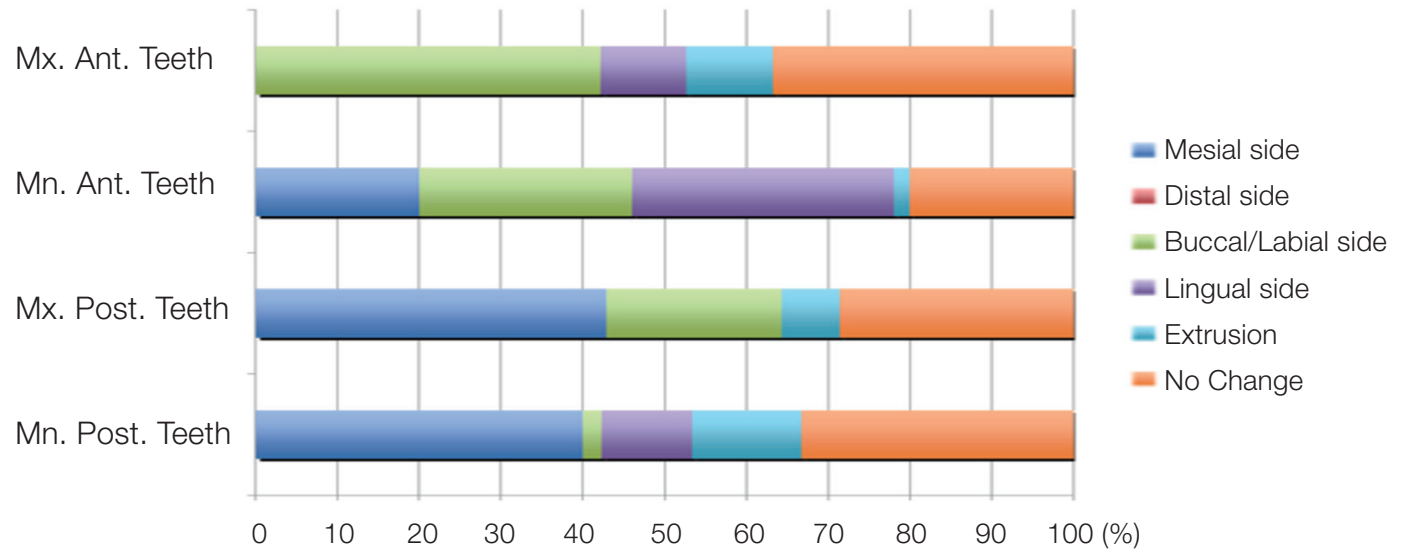

Fig. 3. Proportions of regional displacement directions of natural teeth. 
ment. Mandibular anterior teeth showed combined movement of labial or lingual sides accompanied with mesial drift. On the contrary, movements of maxillary anterior teeth were mainly labial directions. There was anterior flaring of maxilla in the eight models of 13 patients. Attrition was almost seen in every single tooth.

The mean elapsed time of ICL after implant restoration was $61.47 \pm 31.27$ months. The mean interproximal gap was $0.33 \pm 0.14 \mathrm{~mm}$ in width. There were no statistical correlations between interproximal gap width and the elapsed time after implant restoration $(P>.05)$. Age also did not show a significant relationship with the interproximal gap width $(P$ $>$.05).

\section{DISCUSSION}

This study was conducted to analyze displacement of adjacent natural teeth, which is the cause of ICL $^{12}$ in the posterior implant restoration in patients who suffered from food impaction. For comparison of visual and quantitative chronologic change, an initial dental cast of delivery and a dental cast of ICL after function were scanned respectively, and digital models were superimposed on each other. It is very important to examine the movements of adjacent natural teeth with respect to the possibility of total occlusion change in mixed dentition of natural tooth and implant, in addition to harmful effect on peri-implant conditions from food impaction in the area of ICL. Because occurrence of ICL is based on the movement of teeth and tooth movement cannot happen without occlusion change, this doubt is a reasonable inference.

Tooth movements occur from combined effects of various factors: dentofacial change, ${ }^{27}$ compensatory changes due to tooth wear, opposite or adjacent tooth loss, ${ }^{28,29}$ tooth inclination and angulation, ${ }^{17}$ occlusal curvature, ${ }^{30,31}$ parafunction, periodontal disease, general health condition, and medication. ${ }^{32}$ These factors affect at the same time or sequentially to make local or total displacement of adjacent teeth to implant restorations.

Contact loss occurred most likely in the mesial aspect of implant restorations in previous studies. ${ }^{9-11,33}$ The present study showed mesial interproximal contact loss of all cases, but most of cases $(12 / 17)$ were restorations for free-end without bounded distal tooth. Most dentitions show mesial tilting of tooth and anterior component of occlusal force. Wolpoff ${ }^{15}$ proposed a hypothesis in his anthropologic study that the mesial tilting of dental crowns with respect to the roots and jaw movements during occlusion was to develop the interstitial wear. Herber et al. ${ }^{17}$ verified Wolpoff's hypothesis by elucidating the inherent distal drift of rat molar with micro-X-ray computed tomography, SEM, fluorochrome labeling, histology, and immunohistochemistry. They observed ongoing bone formation of the mesial side and resorption of the distal side of the root, by load-mediated subsequent adaptation of the rat dentoalveolar complex. Southard et al. ${ }^{16}$ reported that the anterior component of occlusal force progresses anteriorly through proximal contacts and can pass beyond the dental midline to the contralateral side.

Even after growth spurt, dentition changes continuously. Bishara $e t a l . .^{27}$ conducted the longitudinal investigation to study the dentofacial changes occurring between 25 and 46 years of age. With cephalograms and dental casts available from these subjects, a clinically significant increase in tooth size-arch length discrepancy was found. Carter and McNamara ${ }^{34}$ examined changes in the dental arches that occur in untreated persons between late adolescence and the fifth or sixth decade of life. They concluded there were statistically significant decrements in arch width, depth, and perimeter from their longitudinal study. Harris ${ }^{35}$ from his longitudinal study over the cases of 30 years, drew the conclusion that arch widths increased over time, whereas arch lengths decreased. On the other hand, Bishara et al. ${ }^{27}$ reported that a significant crowding occurred in the mandibular arch over the span of the study. Decrease of arch perimeter with aging is supposed to be the main cause of mandibular incisor crowding. ${ }^{16,36}$ This was coincident with the result of the present study. On the contrary to mesial drift of (pre) molars of maxilla or mandible, mandible incisors moved labio-lingually with mesial drift. This change resulted in incisor crowding and maxilla incisor flaring instead of mesial drift. Occluding to mandibular incisor crowding, maxillary incisors were subjected to outward vector to increase labial inclination.

In the present study, extrusion pattern of adjacent tooth could not be understood easily in the environment of opposite tooth existence. In spite of that, superimposed models showed extrusion pattern after function, which means simultaneous change of opposite dentition. Therefore, ICL and maxilla or mandible tooth movement could not be explained without total occlusion change of arches between the relative positions of implant restoration. Regarding unchangeable implant restoration, natural tooth displacement and occlusion change could also affect occlusion of implant restoration theoretically. In the future, prospective study focused on the occlusion change in the tooth-implant mixed dentition of ICL patient is needed.

Koori et al. ${ }^{9}$ speculated that the loss of interproximal contact at the mesial aspect could decrease when the adjacent teeth are splinted. Pang et al..$^{33}$ also reported that root shape was a contributing factor of ICL. On the other hand, Byun et al. ${ }^{10}$ claimed splinted implant was a contributing factor of ICL rather than splinted teeth. In the present study, 6 of 17 adjacent teeth of ICL areas were splinted and the movement direction of adjacent tooth appeared differently depending on whether they were splinted or not. Except in one case of posterior mandibular cases where changes to lingual side were seen, splinted adjacent teeth were all found to have undergone mesial side migration. In contrast, as for the adjacent teeth that were not splinted, it was seen that 6 of 11 areas underwent mesial side migration, 4 cases showed extrusion, and 1 case showed clockwise rotation. As seen in the results on the displacements of adjacent teeth and residual teeth in the same arch, despite of the general mesial 
movement of natural teeth, each tooth displacement seemed to be affected by occlusal condition, location, and splinting of the tooth, etc.

The calculated average width of interproximal gap was $0.33 \pm 0.14 \mathrm{~mm}$ and mean elapsed time was $61.47 \pm 31.27$ months in this study. However, it is the result based on a small selected number of patients satisfying inclusion criteria, so it cannot be overstated. In the previous studies, first ICL was detected after 3, 6, 8 months of function. ${ }^{8,10,37}$ Moreover, previous studies reported that the ICL incidence supposedly tends to increase over time after implant restoration..$^{8-10,37}$ However, Pang et al. ${ }^{33}$ showed that loss frequency disappeared after 1.9-3.6 year-function in their prospective study of 384 implants. In the present study, there were no significant correlations between interproximal gap width and the elapsed time or age. That means combined factors affect ICL because ICL depends on adjacent teeth condition, occlusion, and opposite dentition. Thus, ICL frequency and gap width change were considered to be different according to subjects. Because arch perimeter decrease is not consistent over life time, chronologic measurement of gap width could be interesting issue to examine.

As mentioned above, there has been little discussion about interproximal contact loss according to chronologic changes of natural teeth and modalities to measure interproximal gap width. For this, 3D digital modeling and 3D superimposition were applied with the help of incredibly rapid advances in CAD. Many studies showed reliable accuracy and reproducibility with 3D digital model when compared with dental cast. ${ }^{38,39}$ Measurement of tooth movement with CAD software is relatively simple compared to $\mathrm{x}$-ray analysis or study model analysis. Moreover, various functions such as slice cut analysis or enlargement tool could be useful for complex tooth displacement.

Until now, various matching landmarks have been suggested for accurate 3D superimposition in dental arches. Some reports suggested that the maxillary palatal rugae was a clinically reliable landmark for assessing orthodontic tooth movements in 3D maxillary superimposition model. ${ }^{24,40}$ However, selection of mandibular landmark is not easy. In the present study, superstructure of osseointegrated implant, which is a fixed element, was considered as a reliable landmark. Many studies reported that the osseointegrated implant does not follow skeletal growth and dentoalveolar complex changes..$^{20,21,23}$ Therefore, a surface to surface superimposition was performed based on the implant supported prostheses and the gingiva near implant area in this study.

The present study has some limitation of data collection from small number of patients satisfying inclusion and exclusion criteria for chronologic changes of dentition in the retrospective study. Therefore, present results of selected patients may not represent real occurrence or prevalence of ICL.

We set recognition of food impaction as elapsed time of ICL. However, in Varthis et al.'s ${ }^{11}$ study in which 'ICL' terminology was first introduced, only $40 \%$ of those who had ICL presented food impaction. Byun et al. ${ }^{10}$ also stated simi- lar pattern that $63 \%$ reported food impaction in the proximal contact loss group. Therefore, ICL could occur earlier than elapsed time we recorded.

Future studies have to conduct a prospective study to analyze chronologic change of interproximal gap. Contrary to the present study measuring one arch of ICL, both arches have to be included to investigate characteristics of dentition and correlation of occlusion as contributing factors of ICL.

\section{CONCLUSION}

Within the limitation of this retrospective study, all interproximal contact loss occurred at a mesial side of implant restoration and natural teeth showed various directional displacements to result in occlusion change in the arch. Although general direction of the natural teeth was mesial direction, the tooth displacement seemed to be affected by occlusal condition, location, and splinting of the tooth. Interproximal gap width was not correlated with elapsed time of ICL or with age. The 3D superimposition of chronologic digital models was an easy and helpful method to analyze the changes of dentition and the individual tooth displacement adjacent to implant supported fixed partial prosthesis. It was possible to conclude that the results would contribute substantially in an overall understanding of teeth displacement and ICL occurrence.

\section{ORCID}

Deuk-Won Jo bttps://orcid.org/0000-0002-3646-4275

Min-Jung Kwon https://orcid.org/0000-0002-5546-7615

Jong-Hee Kim https://orcid.org/0000-0002-6137-5389

Young-Kyun Kim bttps://orcid.org/0000-0002-7268-3870

Yang-Jin Yi https://orcid.org/0000-0001-8341-4759

\section{REFERENCES}

1. Blanes RJ, Bernard JP, Blanes ZM, Belser UC. A 10-year prospective study of ITI dental implants placed in the posterior region. II: Influence of the crown-to-implant ratio and different prosthetic treatment modalities on crestal bone loss. Clin Oral Implants Res 2007;18:707-14.

2. Lekholm U, Gunne J, Henry P, Higuchi K, Lindén U, Bergström C, van Steenberghe D. Survival of the Brånemark implant in partially edentulous jaws: a 10-year prospective multicenter study. Int J Oral Maxillofac Implants 1999;14:63945.

3. Naert I, Koutsikakis G, Duyck J, Quirynen M, Jacobs R, van Steenberghe D. Biologic outcome of implant-supported restorations in the treatment of partial edentulism. part I: a longitudinal clinical evaluation. Clin Oral Implants Res 2002;13:3819.

4. Goodacre CJ, Kan JY, Rungcharassaeng K. Clinical complications of osseointegrated implants. J Prosthet Dent 1999;81:53752.

5. Göthberg C, Bergendal T, Magnusson T. Complications after 
treatment with implant-supported fixed prostheses: a retrospective study. Int J Prosthodont 2003;16:201-7.

6. Kim Y, Oh TJ, Misch CE, Wang HL. Occlusal considerations in implant therapy: clinical guidelines with biomechanical rationale. Clin Oral Implants Res 2005;16:26-35.

7. Pjetursson BE, Lang NP. Prosthetic treatment planning on the basis of scientific evidence. J Oral Rehabil 2008;35:72-9.

8. Wei H, Tomotake Y, Nagao K, Ichikawa T. Implant prostheses and adjacent tooth migration: preliminary retrospective survey using 3-dimensional occlusal analysis. Int J Prosthodont 2008;21:302-4.

9. Koori H, Morimoto K, Tsukiyama Y, Koyano K. Statistical analysis of the diachronic loss of interproximal contact between fixed implant prostheses and adjacent teeth. Int J Prosthodont 2010;23:535-40.

10. Byun SJ, Heo SM, Ahn SG, Chang M. Analysis of proximal contact loss between implant-supported fixed dental prostheses and adjacent teeth in relation to influential factors and effects. A cross-sectional study. Clin Oral Implants Res 2015;26:709-14.

11. Varthis S, Randi A, Tarnow DP. Prevalence of interproximal open contacts between single-implant restorations and adjacent teeth. Int J Oral Maxillofac Implants 2016;31:1089-92.

12. Varthis S, Tarnow DP, Randi A. Interproximal open contacts between implant restorations and adjacent teeth. Prevalence causes - possible solutions. J Prosthodont 2019;28:e806-10.

13. Downs M. Mesial drift. Angle Orthod 1938;8:77-99.

14. Trauner F. The causes of progressive movement of the teeth toward the front. Am Orthod 1912;3:144-58.

15. Wolpoff MH. Interstitial wear. Am J Phys Anthropol 1971; 34:205-27.

16. Southard TE, Behrents RG, Tolley EA. The anterior component of occlusal force. Part 1. Measurement and distribution. Am J Orthod Dentofacial Orthop 1989;96:493-500.

17. Herber RP, Fong J, Lucas SA, Ho SP. Imaging an adapted dentoalveolar complex. Anat Res Int 2012;2012:782571.

18. Ten Cate AR, Deporter DA, Freeman E. The role of fibroblasts in the remodeling of periodontal ligament during physiologic tooth movement. Am J Orthod 1976;69:155-68.

19. Proffit WR, Fields HW, Sarver DM. Contemporary orthodontics. 5th ed. St. Louis; Mosby Elsevier; 2014. p. 278.

20. Thilander B, Odman J, Jemt T. Single implants in the upper incisor region and their relationship to the adjacent teeth. An 8-year follow-up study. Clin Oral Implants Res 1999;10:34655.

21. Jemt T. Measurements of tooth movements in relation to single-implant restorations during 16 years: a case report. Clin Implant Dent Relat Res 2005;7:200-8.

22. Roberts WE, Smith RK, Zilberman Y, Mozsary PG, Smith RS. Osseous adaptation to continuous loading of rigid endosseous implants. Am J Orthod 1984;86:95-111.

23. Bernard JP, Schatz JP, Christou P, Belser U, Kiliaridis S. Longterm vertical changes of the anterior maxillary teeth adjacent to single implants in young and mature adults. A retrospective study. J Clin Periodontol 2004;31:1024-8.

24. Cha BK, Lee JY, Jost-Brinkmann PG, Yoshida N. Analysis of tooth movement in extraction cases using three-dimensional reverse engineering technology. Eur J Orthod 2007;29:325-31.
25. Hoggan BR, Sadowsky C. The use of palatal rugae for the assessment of anteroposterior tooth movements. Am J Orthod Dentofacial Orthop 2001;119:482-8.

26. Choi JI, Cha BK, Jost-Brinkmann PG, Choi DS, Jang IS. Validity of palatal superimposition of 3-dimensional digital models in cases treated with rapid maxillary expansion and maxillary protraction headgear. Korean J Orthod 2012;42:23541.

27. Bishara SE, Treder JE, Jakobsen JR. Facial and dental changes in adulthood. Am J Orthod Dentofacial Orthop 1994;106:17586.

28. Kaplan P. Drifting, tipping, supraeruption, and segmental alveolar bone growth. J Prosthet Dent 1985;54:280-3.

29. Craddock HL. Occlusal changes following posterior tooth loss in adults. Part 3. A study of clinical parameters associated with the presence of occlusal interferences following posterior tooth loss. J Prosthodont 2008;17:25-30.

30. Ito H, Okimoto K, Mizumori T, Terada Y, Maruyama T. A clinical study of the relationship between occlusal curvature and craniomandibular disorders. Int J Prosthodont 1997;10:7882.

31. Sakaguchi K, Uehara S, Yagi T, Miyawaki S. Relationship between occlusal curvatures and bite force in humans. Orthod Wave 2012;71:79-84.

32. Brunsvold MA. Pathologic tooth migration. J Periodontol 2005;76:859-66.

33. Pang NS, Suh CS, Kim KD, Park W, Jung BY. Prevalence of proximal contact loss between implant-supported fixed prostheses and adjacent natural teeth and its associated factors: a 7-year prospective study. Clin Oral Implants Res 2017;28:15018.

34. Carter GA, McNamara JA Jr. Longitudinal dental arch changes in adults. Am J Orthod Dentofacial Orthop 1998;114:8899.

35. Harris EF. A longitudinal study of arch size and form in untreated adults. Am J Orthod Dentofacial Orthop 1997;111:41927.

36. Sinclair PM, Little RM. Maturation of untreated normal occlusions. Am J Orthod 1983;83:114-23.

37. Wong AT, Wat PY, Pow EH, Leung KC. Proximal contact loss between implant-supported prostheses and adjacent natural teeth: a retrospective study. Clin Oral Implants Res 2015;26:e68-71.

38. Quimby ML, Vig KW, Rashid RG, Firestone AR. The accuracy and reliability of measurements made on computer-based digital models. Angle Orthod 2004;74:298-303.

39. Mullen SR1, Martin CA, Ngan P, Gladwin M. Accuracy of space analysis with emodels and plaster models. Am J Orthod Dentofacial Orthop 2007;132:346-52.

40. Miller RJ, Kuo E, Choi W. Validation of Align Technology's Treat III digital model superimposition tool and its case application. Orthod Craniofac Res 2003;6:143-9. 